\title{
Attitudes of Saudi Arabian Undergraduate Medical Students towards Health Research
}

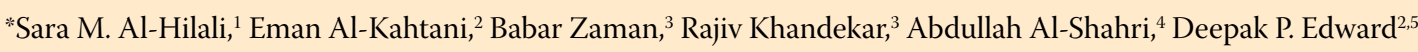

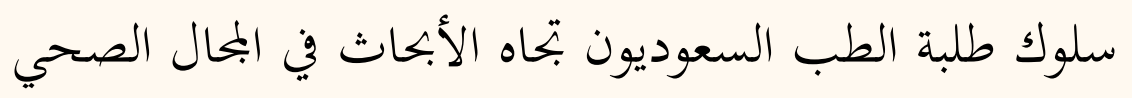

سارة محمد الهلالي، إيمان القحطاني، بابار زمان، راجيف خاندكار، عبداله الشهري، ديباك إدوارد

ABSTRACT: Objectives: This study aimed to evaluate attitudes, perceptions and perceived barriers towards health research among Saudi Arabian undergraduate medical students. Methods: This cross-sectional study took place between August and October 2014 and included 520 students from five medical schools across Saudi Arabia. An anonymous online survey with 21 close-ended questions was designed to assess students' attitudes towards research, contribution to research-related activities, awareness of the importance of research, perception of available resources/opportunities for research, appreciation of medical students' research contributions and perceived barriers to research. Responses were scored on a 5-point Likert scale. Results: A total of 401 students participated in the study (response rate: 77.1\%). Of these, 278 (69.3\%) were female. A positive attitude towards research was reported by $43.9 \%$ of the students. No statistically significant differences were observed between genders with regards to attitudes towards and available resources for research $(P=0.500$ and 0.200 , respectively). Clinical students had a significantly more positive attitude towards research compared to preclinical students $(P=0.007)$. Only $26.4 \%$ of the respondents believed that they had adequate resources/opportunities for research. According to the students, perceived barriers to undertaking research included time constraints $(\mathrm{n}=200 ; 49.9 \%)$, lack of research mentors $(n=95 ; 23.7 \%)$, lack of formal research methodology training $(n=170 ; 42.4 \%)$ and difficulties in conducting literature searches $(n=145 ; 36.2 \%)$. Conclusion: Less than half of the surveyed Saudi Arabian medical students had a positive attitude towards health research. Medical education policies should aim to counteract the barriers identified in this study.

Keywords: Research; Medical Students; Attitudes; Perceptions; Medical Education; Saudi Arabia.

الملخص: الههف: هدف البحث إلى تقييم سلوك وتصورات طلاب الطب السعوديون، والعقبات الملحوظة من قبلهم نحو إجراء الأبحاث في

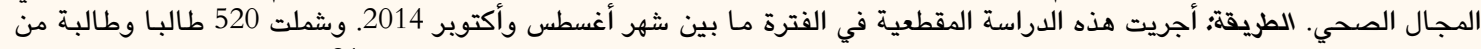

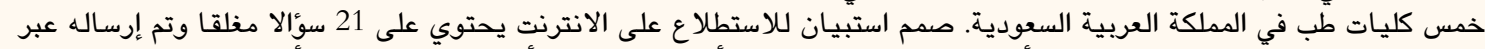

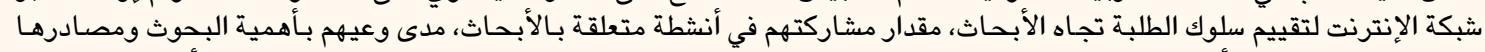

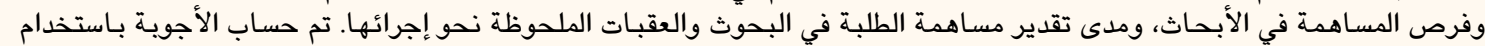

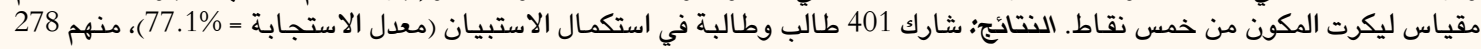

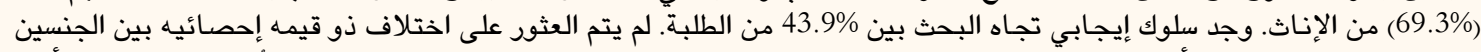

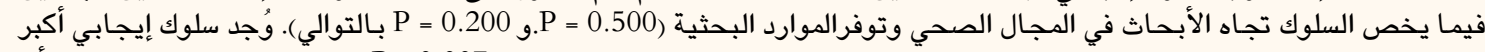

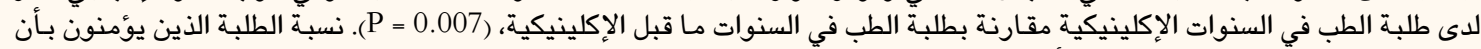

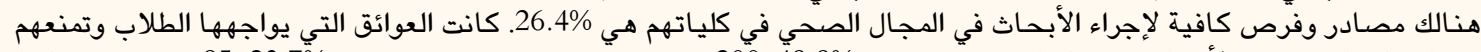

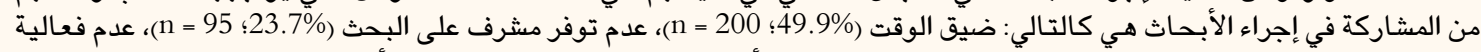

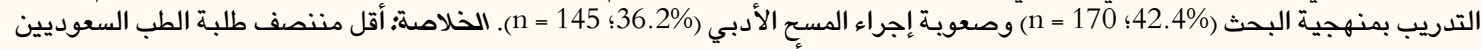

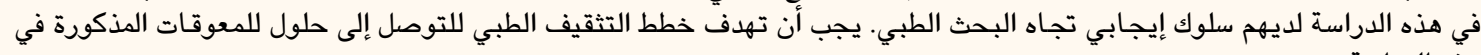
هذه الدراسة.

$$
\text { مفتاح الكلمات: بحث؛ طلبة الطب؛ سلوك؛ تصورات؛ التعليم الطبي؛ المملكة العربية السعودية. }
$$

\footnotetext{
Advances in KNOwhedge

To the best of the authors' knowledge, this study is the first to investigate the attitudes and perceptions of Saudi Arabian medical students towards health research.

Less than half of the surveyed medical students were found to have a positive attitude towards research.

\section{Application to Patient Care}

Understanding of the attitudes and barriers faced by undergraduate medical students with regards to research may help educators to identify key areas that need to be addressed in medical education.
} 
Positive attitudes towards scientific research among undergraduate medical students is likely to enhance the quality of future patient care.

\section{$\mathrm{T}$} HE NUMBER OF PHYSICIAN-SCIENTISTS IN medical practice is declining; over the last two decades, the number of physician-scientists on staff at medical school faculties has decreased by nearly $25 \% .^{1-3}$ This suggests that the learning environment in medical schools is not conducive to clinical and basic research. ${ }^{2,3}$ While certain medical schools do include instruction in research methodologies within their curricula, it is also essential to evaluate how medical students respond to these strategies in order to further enhance their medical education. To date, most of the data regarding medical students' attitudes and perceptions towards research have originated from industrialised countries. ${ }^{1-4}$

Saudi Arabia is the largest country in the Middle East, with a gross domestic product of USD \$24,911 per capita. ${ }^{5}$ Over the last decade, there has been a significant shift in medical education in Saudi Arabia and surrounding countries in the Gulf Cooperation Council (GCC) region; Saudi Arabia is currently moving towards a knowledge-based economy, of which research is an important component. ${ }^{6,7} \mathrm{New}$ medical schools have been established and large numbers of medical graduates are expected over the next decade. Other GCC and Southeast Asian countries also have greater numbers of graduating medical students and are opening new medical schools. ${ }^{8,9}$ In Saudi Arabia, national efforts are increasingly focused on strengthening the education and health systems; in 2014, 6.9\% of government expenditures were directed towards the health sector and there were almost 1,200 medical graduates from Saudi Arabian schools in 2009. ${ }^{7,10}$ The government promotes evidence-based education and policy-making within the medical community. ${ }^{11}$ Evidence suggests that Saudi Arabian medical students are increasingly participating in and contributing to health research. ${ }^{12}$

The development of a positive attitude towards scientific research is a fundamental element of modern undergraduate medical education. ${ }^{13}$ However, to the best of the authors' knowledge, there is a paucity of data regarding undergraduate medical students' attitudes towards research and their perceptions of available resources and opportunities for research. Additionally, no studies from Saudi Arabia on this topic yet exist in the peer-reviewed literature. This study therefore aimed to evaluate attitudes and perceived barriers towards participating in health-based research among a cohort of Saudi Arabian undergraduate medical students.

\section{Methods}

This cross-sectional study took place between August and October 2014 and included undergraduate medical students from medical schools across Saudi Arabia. For an estimated population of 3,900 Saudi Arabian medical students, a sample size of at least 407 respondents $(370+10 \%$ to compensate for nonparticipation) was needed to achieve a $95 \%$ confidence interval and a $7 \%$ margin of error with a study design effect of two. ${ }^{14}$ To calculate the sample size, it was assumed that $57 \%$ of medical students were involved in research projects. ${ }^{1}$ At least one university from each of the central, eastern, western and northern regions of Saudi Arabia were contacted for permission to access their email database of medical students; of these, six universities (one private and five public universities) from the central, eastern and western regions gave their consent. Five of the six medical schools were randomly selected and all 520 students of these schools were included in the study. Two senior researchers and two medical students were field investigators for the study. First- and second-year students were grouped as preclinical students and students in their third, fourth and fifth years of medical school were grouped as clinical students.

An anonymous self-reported online survey was developed by an information technology expert from the Research Department of the King Khaled Eye Specialist Hospital in Riyadh, Saudi Arabia. The English-language survey was based on a previously validated survey and used LimeSurvey ${ }^{\mathcal{O}}$ (LimeSurvey Project, Hamburg, Germany). ${ }^{1}$ A pilot study on 10 medical students who were excluded from the subsequent study was performed to ensure that the survey was easily accessible and that the language utilised was appropriate and clear. Based on the results of the pilot study, no changes to the questionnaire were required. The survey included 21 close-ended questions to determine the students' demographic information, past contributions to research-related activities, awareness of the importance of research, attitudes towards health-based research, perceptions of available resources/opportunities for research, appreciation of medical students' contributions to research and perceived barriers to research.

Each questionnaire item was scored on a 5-point Likert scale; positive responses (completely agree and agree) received scores of 2 and 1 , respectively, while negative responses (completely disagree and disagree) 
Table 1: Participation in and perceptions of healthbased research among surveyed Saudi Arabian undergraduate medical students $(\mathrm{N}=401)$

\begin{tabular}{|c|c|c|}
\hline Item & n (\%) & 95\% CI \\
\hline Participation in research projects & $278(69.3)$ & $64.8-73.8$ \\
\hline $\begin{array}{l}\text { Participation in medical school } \\
\text { research projects }\end{array}$ & $250(62.3)$ & $57.6-67.1$ \\
\hline $\begin{array}{l}\text { Publication of research papers } \\
\text { as first author in peer-reviewed } \\
\text { journals }\end{array}$ & $13(3.2)$ & $1.5-5.0$ \\
\hline $\begin{array}{l}\text { Positive attitude towards } \\
\text { research }\end{array}$ & $178(44.4)$ & $39.5-49.3$ \\
\hline $\begin{array}{l}\text { Adequate resources/ } \\
\text { opportunities for research }\end{array}$ & $106(26.4)$ & $22.1-30.7$ \\
\hline $\begin{array}{l}\text { Appreciation of contribution to } \\
\text { research }\end{array}$ & $161(40.2)$ & $35.2-44.8$ \\
\hline
\end{tabular}

received scores of -2 and -1 , respectively. A score of zero was given to neutral answers (do not know). Total scores for questions in each category were then summed and divided by the maximum possible score in order to calculate the percentage proportion of the score. Percentages $>75 \%$ were considered to be positive.

Data were analysed using the Statistical Package for the Social Sciences (SPSS), Version 22 (IBM Corp., Chicago, Illinois, USA). A univariate analysis was performed to calculate frequencies and proportions of the responses. To compare responses by gender, odds ratios and $95 \%$ confidence intervals were estimated. To review the frequency of responses by academic year, a Chi-squared analysis was performed. A $P$ value of $<0.050$ was considered statistically significant.

The Institutional Research Board at the King Khaled Eye Specialist Hospital granted ethical approval for this study (\#1467-P). As responses were anonymous, the written consent of participants was waived; however, the online survey began with a participation agreement form. Additionally, an introductory email was sent with each survey confirming the voluntary nature of participation and stating the research objectives of the study.

\section{Results}

A total of 401 respondents participated in the survey (response rate: 77.1\%), including 123 (30.7\%) male and 278 (69.3\%) female students. The proportion of students within each academic year was similar and the number of students per year ranged from 73-102 (18.2-25.4\%). A positive attitude towards research was reported by 178 respondents (44.4\%) and 106 (26.4\%) believed that they had adequate resources/ opportunities for research in their medical school
Table 2: Variations by gender in perceptions of health-based research among surveyed Saudi Arabian undergraduate medical students $(\mathrm{N}=401)$

\begin{tabular}{|c|c|c|c|c|}
\hline \multirow[t]{2}{*}{ Item } & \multicolumn{2}{|c|}{ n (\%) } & \multirow{2}{*}{$\begin{array}{c}\text { OR } \\
(95 \% \mathrm{CI})\end{array}$} & \multirow{2}{*}{$\begin{array}{c}\text { P } \\
\text { value }\end{array}$} \\
\hline & $\begin{array}{c}\text { Male } \\
(\mathrm{n}=123)\end{array}$ & $\begin{array}{c}\text { Female } \\
(\mathbf{n}=278)\end{array}$ & & \\
\hline \multicolumn{3}{|c|}{ Attitude towards research } & $\begin{array}{c}1.2 \\
(0.8-1.8)\end{array}$ & 0.500 \\
\hline Positive & $58(47.1)$ & $120(43.2)$ & & \\
\hline Negative & 65 (52.9) & $158(56.8)$ & & \\
\hline \multicolumn{3}{|c|}{ Resources/opportunities for research } & $\begin{array}{c}1.4 \\
(0.9-2.2)\end{array}$ & 0.200 \\
\hline Adequate & $38(30.9)$ & $68(24.5)$ & & \\
\hline Inadequate & $85(69.1)$ & $210(75.5)$ & & \\
\hline \multicolumn{3}{|c|}{ Appreciation of contribution to research } & $\begin{array}{c}2.0 \\
(1.3-3.1)\end{array}$ & 0.001 \\
\hline Appreciation & $64(52.0)$ & $97(34.9)$ & & \\
\hline $\begin{array}{l}\text { Lack of } \\
\text { appreciation }\end{array}$ & $59(48.0)$ & $181(65.1)$ & & \\
\hline
\end{tabular}

[Table 1]. Of the participants, 188 (46.9\%) were aware of the usefulness of research in achieving their longterm medical career goals and 233 (58.1\%) were aware of the importance of research in medical education.

Gender variations in attitudes towards and perceptions of available resources/opportunities for research were not statistically significant $(P=0.500$ and 0.200 , respectively). However, significantly more male students appreciated contributions to research compared to female students $(P=0.001)$ [Table 2]. Clinical students had a significantly more positive attitude towards research compared to their preclinical counterparts $(P=0.007)$. In addition, significantly more clinical students believed they had adequate resources/ opportunities for research compared to preclinical students $(P=0.007)$; however, the difference was not significant with regards to appreciation of research contributions $(P=0.060)$ [Table 3].

According to the participants, there were several perceived barriers to undertaking research. These included time constraints ( $\mathrm{n}=200 ; 49.9 \%$ ), lack of research mentors ( $\mathrm{n}=95 ; 23.7 \%)$, lack of formal research methodology training $(n=170 ; 42.4 \%)$ and lack of training/difficulties in conducting literature searches $(n=145 ; 36.2 \%)$.

\section{Discussion}

Half of the surveyed Saudi Arabian medical students in the current study reported an awareness of the 
Table 3: Variations by academic year in perceptions of health-based research among surveyed Saudi Arabian undergraduate medical students $(\mathrm{N}=401)$

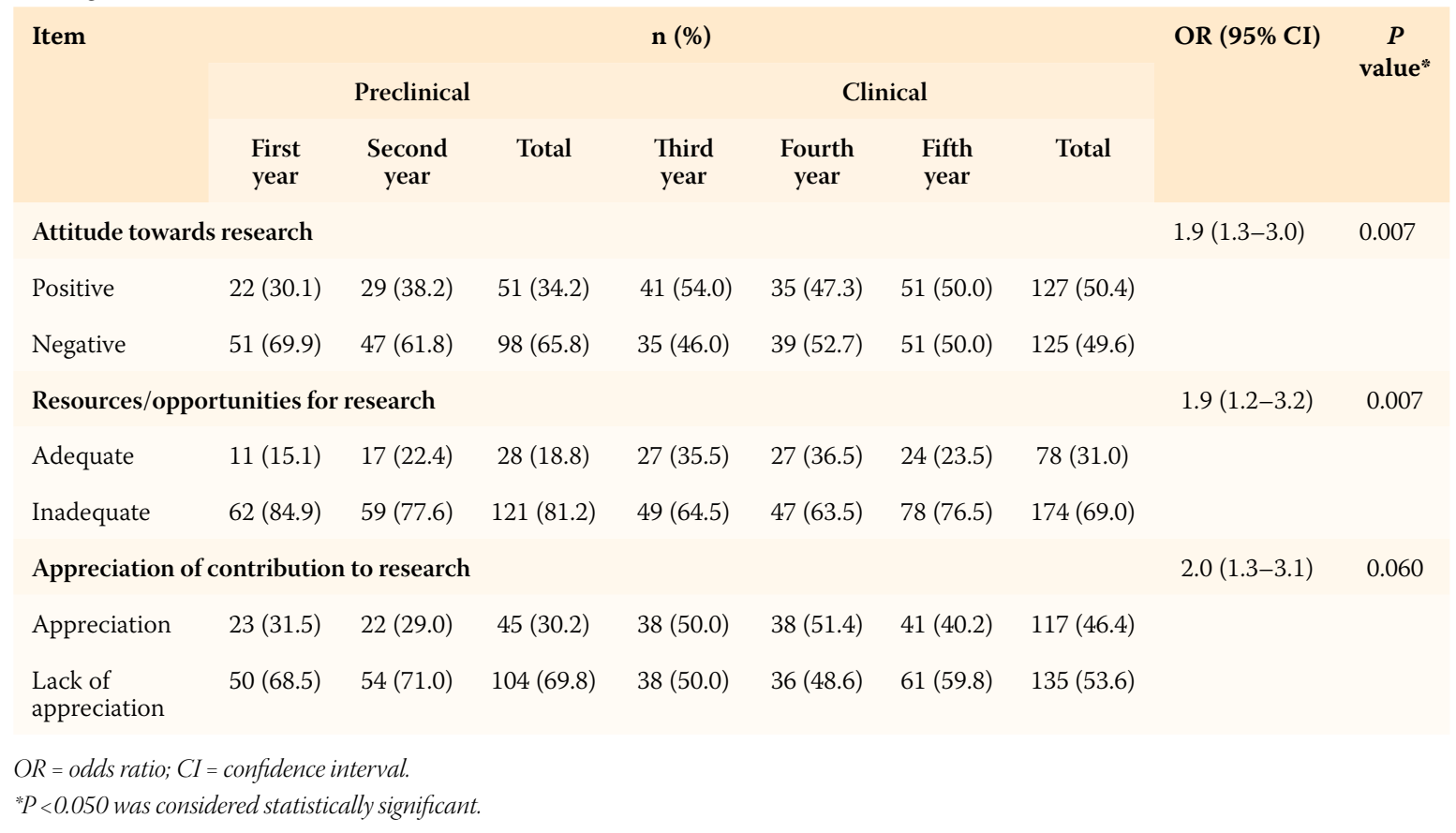

importance of undertaking research. Less than half of the surveyed students had a positive attitude towards participating in research activities. No significant differences in attitudes towards or perceptions of research were noted between genders. However, appreciation for student contributions to research was greater among male students compared to females. Gender equality is an important consideration worldwide, particularly with regards to education. ${ }^{15}$ Although Saudi Arabia was ranked 130 out of 142 countries for gender equality in the Global Gender Gap Report for 2014, the educational attainment score was 0.987, suggesting that Saudi females attain a very high educational level. ${ }^{16}$ Due to their positive attitude towards research evidenced in the present study, educated Saudi females seem to be committed to enhancing education and healthcare through research. The higher number of female participants in the current study is also notable, particularly as the average male-to-female ratio of student enrolment in undergraduate medical education in Saudi Arabia was nearly $3: 1$ in $2011 .{ }^{17}$

In the current study, clinical students were significantly more likely to have a positive attitude towards research than preclinical students, with half of the fifth-year students having a positive attitude compared to less than a third of the first-year students. An increased awareness and maturity among students in their clinical years could explain this observation; this suggests a steady increase in awareness of research throughout the course of a student's medical education. Similarly, Khan et al. found that both knowledge and

attitudes improved significantly the longer a medical student was enrolled in college. ${ }^{18}$ Clinical students in the current study were also significantly more inclined to perceive that they had adequate resources/ opportunities for research compared to students in their preclinical years. In addition, they were more inclined to value contributions to research. Again, this is likely because older students are more likely to be aware of available resources within their respective medical schools. Furthermore, at this stage in their careers, research participation is considered an asset when applying for residency and postgraduate training programmes.

Medical students in the current study revealed four main barriers to conducting research, including time constraints, lack of mentorship and inadequate training in literature searches and research methodology. Similar barriers to research were reported by medical students in Canada. ${ }^{1}$ These results also concur with those of an Irish study which found that lack of time was the greatest barrier to pursuing scientific research among a cohort of undergraduate medical students in the UK. ${ }^{19}$ Unnikrishnan et al. observed that time constraints were the main barrier reported by undergraduate medical students in India; medical professors and mentors also confirmed that time constraints precluded supervision of student research projects. ${ }^{20}$ The second most important factor was limited training in research among undergraduate students. ${ }^{20}$ A randomised controlled trial in the UK found that insufficient instruction on the basics of scientific research in medical colleges hindered 
students from participating in or leading research projects. ${ }^{21}$ Similarities in results between the current study and those of international research suggest that unified solutions should be developed to overcome these obstacles to research participation.

The survey used in the current study assessed the attitudes of medical students towards health research and related factors. A Croatian study reported a more positive attitude towards science among students who took mandatory research courses compared to those who did not. ${ }^{2}$ Another study found that students enrolled in problem-based learning courses had a healthier attitude towards research compared to those participating in lecture-based learning. ${ }^{22}$ This outcome indicates the positive impact of a problem-based curriculum on the attitude of medical students towards health research. ${ }^{22}$ Medical schools should consider offering online self-paced courses to address the issues of time constraints and inadequate training as well as web-based consultancy services to guide students who are interested in conducting research studies. The Saudi Digital Library offers unlimited access to over 310,000 articles and offers tutorials on how to search for content and navigate their website. ${ }^{23}$ Saudi medical students should therefore be encouraged to use this resource. Databases of available qualified research professionals within Saudi Arabia and the GCC region willing to provide mentorship services could also be made available to medical students.

A previous study from Saudi Arabia reported that publications in medical sciences increased between 1996-2012. ${ }^{12}$ This resulted in Saudi Arabia being ranked $45^{\text {th }}$ in the world in 2012 in terms of research productivity. ${ }^{12}$ More than half of the students believed that research was relevant to medical education in Saudi Arabia. These findings imply that, with effective policies and opportunities, current medical students will soon be willing to participate in research and further increase Saudi Arabia's ranking in the near future. Administrative, research and medical education departments in Saudi Arabia should seek to develop policies targeting students to enhance their understanding of the importance of research. Telmesani et al. noted challenges in executing changes in the Saudi medical education system. ${ }^{8}$ They also opined that reforms were directed more toward changing curricula rather than defining the essential skills, knowledge and standards needed for graduating physicians. ${ }^{8}$ The results of the current study indicate a need for reforms that will lead to improved perceptions of research among medical students and increased research productivity within the country.

Certain limitations to the current study should be noted when interpreting the results. The findings were based on responses from a self-reported web-based anonymous survey. Furthermore, there are a total of 28 medical schools in Saudi Arabia; ${ }^{24}$ only six were targeted in this study. Additionally, these schools were highly ranked and may therefore have had greater research-related resources than other universities in Saudi Arabia. Further studies are recommended to survey the attitudes of students from all medical schools in the country. Nevertheless, despite these limitations, it is important to note that participant responses to the anonymous survey used in the current study may have been more honest than those from other research utilising different methods of data collection. ${ }^{25}$

\section{Conclusion}

Half of the surveyed Saudi Arabian medical students were aware of the importance of undertaking research although less than half had a positive attitude towards research. Four main barriers to research participation were identified-time constraints, lack of mentorship and inadequate training in literature searches and research methodology. In order to strengthen the medical research environment in Saudi Arabia, policymakers should take these barriers into account.

\section{CONFLICT OF INTEREST}

The authors declare no conflicts of interest.

\section{References}

1. Siemens DR, Punnen S, Wong J, Kanji N. A survey on the attitudes towards research in medical school. BMC Med Educ 2010; 10:4. doi: 10.1186/1472-6920-10-4

2. Hren D, Lukić IK, Marusić A, Vodopivec I, Vujaklija A Hrabak M, et al. Teaching research methodology in medical schools: Students' attitudes towards and knowledge about science. Med Educ 2004; 38:81-6. doi: 10.1111/j.13652923.2004.01735.x

3. Solomon SS, Tom SC, Pichert J, Wasserman D, Powers AC. Impact of medical student research in the development of physician-scientists. J Investig Med 2003; 51:149-56. doi: 10. 1097/00042871-200305000-00017.

4. Reinders JJ, Kropmans TJ, Cohen-Schotanus J. Extracurricular research experience of medical students and their scientific output after graduation. Med Educ 2005; 39:237. doi: 10.1111/ j.1365-2929.2004.02078.x.

5. Kingdom of Saudi Arabia Ministry of Health. Statistical book for the year 1433. From: www.moh.gov.sa/en/Ministry/ Statistics/book/Documents/1433.pdf Accessed: Aug 2015.

6. King Abdulaziz City for Science and Technology and Kingdom of Saudi Arabia Ministry of Economy and Planning. Strategic technology program summary document. From: www.kacst. edu.sa/en/research/it/Documents/ghq.pdf Accessed: Aug 2015.

7. Althubaiti A, Alkhazim M. Medical colleges in Saudi Arabia: Can we predict graduate numbers? High Educ Stud 2014; 4:1-8. doi: 10.5539/hes.v4n3p1. 
8. Telmesani A, Zaini RG, Ghazi HO. Medical education in Saudi Arabia: A review of recent developments and future challenges. East Mediterr Health J 2011; 17:703-7.

9. Khalid BA. The current status of medical education in the Gulf Cooperation Council countries. Ann Saudi Med 2008; 28:83-8.

10. World Health Organization. Country cooperation strategy at a glance: Saudi Arabia. From: www.who.int/countryfocus/ cooperation_strategy/ccsbrief_sau_en.pdf Accessed:Aug 2015

11. King Abdulaziz City for Science and Technology and Kingdom of Saudi Arabia Ministry of Economy and Planning. Kingdom of Saudi Arabia: Strategic priorities for advanced medical and health research. From: www.kacst.edu.sa/en/research/ Documents/MedicalAndHealth.pdf Accessed: Aug 2015.

12. Meo SA, Hassan A, Usmani AM. Research progress and prospects of Saudi Arabia in global medical sciences. Eur Rev Med Pharmacol Sci 2013; 17:3265-71.

13. O'Mara RJ, Hsu SI, Wilson DR. Should MD-PhD programs encourage graduate training in disciplines beyond conventional biomedical or clinical sciences? Acad Med 2015; 90:161-4. doi: 10.1097/ACM.0000000000000540.

14. Kingdom of Saudi Arabia Ministry of Higher Education. The current status of higher education in the Kingdom of Saudi Arabia:2011. From:he.moe.gov.sa/en/Ministry/General-admini stration-for-Public-relations/BooksList/stat7eng.pdf Accessed: Aug 2015.

15. United Nations. Millennium developmental goals beyond 2015: Goal 3 - Promote gender equality and empower women. From: www.un.org/millenniumgoals/gender.shtml Accessed: Aug 2015.

16. World Economic Forum. The global gender gap report 2014 From: www3.weforum.org/docs/GGGR14/GGGR_Complete Report_2014.pdf Accessed Aug 2015.

17. Abdulghani HM, AlKanhal AA, Mahmoud ES, Ponnamperuma GG, Alfaris EA. Stress and its effects on medical students: A cross-sectional study at a college of medicine in Saudi Arabia. J Health Popul Nutr 2011; 29:516-22. doi: 10.3329/jhpn. v29i5.8906
18. Khan H, Khawaja MR, Waheed A, Rauf MA, Fatmi Z. Knowledge and attitudes about health research amongst a group of Pakistani medical students. BMC Med Educ 2006; 6:54. doi: 10.1186/1472-6920-6-54.

19. Burgoyne LN, O’Flynn S, Boylan GB. Undergraduate medical research: The student perspective. Med Educ Online 2010; 10:15. doi: 10.3402/meo.v15i0.5212.

20. Unnikrishnan B, Kanchan T, Holla R, Kumar N, Rekha T, Mithra P, et al. Medical students' research: Facilitators and barriers. J Clin Diagn Res 2014; 8:XC01-4. doi: 10.7860/JCDR /2014/10223.5291.

21. Parkes J, Hyde C, Deeks J, Milne R. Teaching critical appraisal skills in health care settings. Cochrane Database Syst Rev 2001; CD001270. doi: 10.1002/14651858.cd001270.

22. Khan H, Taqui AM, Khawaja MR, Fatmi Z. Problem-based versus conventional curricula: Influence on knowledge and attitudes of medical students towards health research. PLoS One 2007; 2:e632. doi: 10.1371/journal.pone.0000632.

23. Saudi Digital Library. Policy and user guide From: www.sdl. edu.sa/SDLPortal/EN/UserManual.aspx Accessed: Aug 2015.

24. Kingdom of Saudi Arabia Ministry of Education. Higher education: Study in KSA. From: www.he.moe.gov.sa/en/ studyinside/Pages/default.aspx Accessed: Aug 2015.

25. Alsayed N, Eldeek B, Tayeb S, Ayuob N, Al-Harbi A. Research practices and publication obstacles among interns at King Abdulaziz University Hospital, Jeddah, Saudi Arabia, 2011-2012. J Egypt Public Health Assoc 2012; 87:64-70. doi: 10.1097/01.EPX.0000417978.44502.61. 